\title{
Profissão docente: aspirações de estudantes do ensino médio sobre ser professor de matemática
}

\section{RESUMO}

Leoni Malinoski Fillos leonimfillos@hotmail.com 0000-0002-5110-0234

Universidade Estadual do Centro-oeste do Paraná, Irati, Paraná, Brasil.

Priscila Dombrovski Zen prisciladzen@gmail.com

Universidade Estadual do Centro-oeste do Paraná, Irati, Paraná, Brasil.

Joyce Jaquelinne Caetano joyce.tardo@yahoo.com.br 0000-0002-4566-4201

Universidade Estadual do Centro-oeste do Paraná, Irati, Paraná, Brasil.

\begin{abstract}
Este artigo objetiva discutir a atratividade da carreira docente pela ótica de alunos do 3응 ano do ensino médio, especialmente sobre ser professor de Matemática. A partir de um roteiro com questões abertas e fechadas, buscou-se obter dados quantitativos a respeito das intenções profissionais de estudantes de cinco colégios de um município do interior do Paraná e dados qualitativos sobre os motivos e influências que levaram esses estudantes a desejar ou não a carreira docente. Os dados indicam que os estudantes consideram a profissão docente importante e de muita responsabilidade, porém, a grande maioria não tem a intenção de seguir a carreira de professor, devido à falta de atratividade da profissão. Sobre o desígnio de ser professor de Matemática, o número é praticamente irrisório e as justificativas se resumem em não gostar da disciplina, ter muita dificuldade na assimilação dos conteúdos e não ver sentido do que aprendem na matemática escolar.
\end{abstract}

PALAVRAS-CHAVE: Ensino médio. Escolha profissional. Professor de Matemática. 


\section{INTRODUÇÃO}

A profissão docente não tem se mostrado atrativa no Brasil. Diversas pesquisas apontam que os estudantes concluintes do ensino médio, em sua maioria, não têm interesse pela carreira docente e, mais do que isso, consideram que é uma carreira desprestigiada e uma das que mais apresenta rejeição entre os adolescentes. Se considerarmos a área das ciências exatas, especialmente Matemática, Física e Química, esse desinteresse é ainda maior e tem sido motivo de preocupação de gestores públicos.

De acordo com levantamento realizado pela área de Estudos e Pesquisas da Fundação Victor Civita, coordenado por Gatti et al. (2010), o desprestígio pela carreira docente é alarmante no Brasil, pois somente $2 \%$ dos estudantes do ensino médio desejam cursar Pedagogia ou alguma Licenciatura e outros $9 \%$ mencionam a intenção de cursar áreas voltadas às disciplinas da educação básica, o que não garante que venham a se interessar por lecionar. Dentre os $2 \%$ que desejam lecionar, a grande maioria frequenta escolas públicas e, em geral, tem restrições financeiras para acesso à cultura, como leitura, cinema, teatro, exposições e viagens. Os dados apontam, também, que cursos voltados à formação de professores têm uma relação candidato/vaga nas universidades bastante desfavorável, tendo em vista a baixa procura nos concursos vestibulares e, por consequência, a entrada praticamente de todos os inscritos. Indicam, ainda, um número crescente de vagas ociosas nesses cursos, a decorrente tendência de queda na quantidade de formandos e o envelhecimento do corpo docente. Atualmente, segundo a pesquisa, $41 \%$ dos professores no Brasil têm 41 anos ou mais, ou seja, está relativamente próximo da aposentadoria (GATTI, et al., 2010).

O estudo realizado por Louzano et al. (2010), financiado pela Fundação Lemann e pelo Instituto Futuro Brasil, também buscou levantar dados a respeito da profissão docente e identificar os problemas que o Brasil encontra para selecionar e contratar bons professores para atuar nas escolas. Analisando dados sobre as condições socioeconômicas e sobre os planos futuros dos estudantes que realizaram o Exame Nacional do Ensino Médio (ENEM), os pesquisadores mostram que apenas $11 \%$ de todos os alunos que fizeram o exame tinham interesse em se tornar professores do ensino fundamental ou médio e, entre esses, somente $10 \%$ pertenciam ao grupo dos melhores alunos do ensino médio do país e cerca de um terço deles estavam entre os piores de seu grupo. Ou seja, a pesquisa indica que o Brasil atrai indivíduos com baixo rendimento acadêmico para a carreira docente.

Com relação às áreas de exatas, em estudo que trata da influência do desempenho em Matemática ao longo da educação básica na escolha de carreiras no ensino superior, Gramani e Scrich (2012) apontam a existência de uma correlação negativa com a eficiência educacional em Matemática. A partir da análise dos resultados do ENEM (2008) e dos inscritos em vestibulares por regiões do Brasil, as autoras advertem que as carreiras relacionadas à formação de professores na área de exatas são mais procuradas em estados da federação com menores eficiências na disciplina de Matemática, valendo também o inverso, ou seja, quanto maior a eficiência educacional em Matemática do estado, menor a procura por estes cursos neste estado. Esses dados, segundo Gramani e Scrich (2012, p. 14), corroboram a preocupação de Passos (2005), isto é, "alunos que não gostam de matemática serão professores e, provavelmente, formarão alunos que 
também não gostarão de matemática e que poderão procurar cursos de magistério".

Nesse contexto, este artigo traz os resultados de uma pesquisa que buscou investigar a atratividade da carreira docente pela ótica de alunos do 3ㅇ ano do ensino médio, de um município da região Centro Sul do Paraná. No estudo, buscouse obter dados quantitativos a respeito das intenções profissionais e do perfil dos estudantes, bem como dados qualitativos sobre os motivos e influências que levaram esses estudantes a desejar ou não a carreira docente, em especial, em cursar Licenciatura em Matemática.

\section{A profissão docente no Brasil: algumas reflexões}

A palavra professor deriva do latim professum que, por sua vez, vem do verbo profiteri, formado por fateri (confessar), com o prefixo pro (diante de todos, à vista). Traz a ideia de professar, que significa confessar publicamente, manifestarse, declarar em alto e bom som, afirmar, assegurar. Indo um pouco além nas definições, é possível constatar que aquele que professa é também aquele que confessa, que abraça uma causa, que adota um ideal (SILVA, 2010). Em dicionários, são sinônimos da palavra professor: mestre, lente, educador, mentor, preceptor, preletor, prelecionador. No dicionário Houaiss (2001), a primeira acepção da palavra "professor" refere-se a alguém que "professa uma crença, uma religião"; também àquele "cuja profissão é dar aulas em escola, colégio ou universidade" e àquele "que transmite algum ensinamento a outra pessoa".

A literatura educacional traz o professor como o grande agente do processo educativo e um alicerce na formação científica, cidadã e humana do estudante. Ele tem papel determinante nas escolas na garantia do acúmulo de conhecimentos científicos e, ao mesmo tempo, no desenvolvimento de valores e atitudes de segurança, investigação e reflexão do estudante. Para Chalita (2001), por mais que se invista em escolas com equipados laboratórios, bibliotecas, modernas salas de aula ou quadras esportivas, sem negar a importância de tais espaços, "tudo isso não se configura mais do que aspectos materiais se comparados ao papel e à importância do professor" (p. 163). Ele tem a missão de gerenciar o processo de ensino de aprendizagem, interagir com o aluno na produção e crítica de novos conhecimentos, tendo responsabilidades também na inserção do estudante no mundo do trabalho e no seu convívio autônomo na sociedade.

Mizukami (1996) enfatiza que o professor é o principal mediador entre os conhecimentos socialmente construídos e o aluno e isso independe da área específica de conhecimento, linha teórica e/ou proposta pedagógica adotada (assumida individual ou coletivamente), nível de ensino e tipo de escola em que atua. O professor, segundo a autora, é ao mesmo tempo um membro de uma classe profissional e um aprendiz e, igualmente, fonte de modelos, crenças, valores, atitudes, conceitos e pré-conceitos que constituem, ao lado do conteúdo específico da disciplina ensinada, outros tipos de conteúdos que são por ele mediados.

O professor exerce, portanto, um papel de fundamental importância para a formação cidadã dos sujeitos e para o desenvolvimento de uma sociedade como um todo. Por isso, quando se fala em educação de qualidade, aspectos fundamentais para a profissionalização da atividade docente deveriam receber 
tratamento adequado na pauta das políticas educacionais a fim de estimular adolescentes e jovens a seguir a carreira docente. Estes, porém, percebem, ao longo de seus anos estudantis, que entre seus professores há um desconforto causado pelas crescentes exigências da profissão, concomitante a um descontentamento no que se refere ao decrescente prestígio social (TARTUCE; NUNES; ALMEIDA, 2010).

Para Lima (1996), a profissão docente é uma atividade extremamente complexa, ambígua e contraditória, sendo percebida como não atrativa por uma parcela significativa dos que pretendem ingressar no ensino superior. A ambiguidade, segundo o autor, se manifesta quando se considera o estatuto social do professor, ou seja, apresenta nível econômico relativamente baixo, se comparado com outras profissões de formação acadêmica análoga, porém nível cultural acima da média, tendo em vista a posse do diploma e o prestígio daí decorrente. Já o caráter contraditório se revela quando se exige, por exemplo, que o professor estimule os alunos mais rápidos nas atividades escolares propostas, mas acompanhe aqueles que trabalham lentamente; ou quando se exige que o professor exerça autoridade, mantendo a disciplina da turma que leciona, e, ao mesmo tempo, tenha com os alunos um comportamento afetivo, sendo simpático e cordial (LIMA, 1996). Ser professor, contraditoriamente, "significa tomar decisões pessoais e individuais constantes, porém sempre reguladas por normas coletivas, as quais são elaboradas por outros profissionais ou regulamentos institucionais" (FELZ, 2003, p. 04).

Ao contrário de muitas funções, os professores, em geral, têm de lidar com diversos estudantes em simultâneo, estando constantemente à mercê de um público cujas características e comportamentos são muitas vezes desconhecidos e imprevisíveis. Além das responsabilidades cada vez maiores em relação às atividades pedagógicas, questões que extrapolam a mediação com o conhecimento, como a violência e as drogas, estão cada vez mais presentes nas conflituosas salas de aula, repletas de alunos aborrecidos e cheios de mecanismos de fuga e de defesa (FELZ, 2003).

Outros problemas que interferem direta ou indiretamente sobre a atratividade da carreira docente estão relacionados ao decrescente prestígio social, que se traduzem nas precárias condições de trabalho (turmas superlotadas, sucateamento de escolas, falta de materiais didáticos), baixos salários, desvalorização e falta de plano de carreira.

A questão salarial, em especial, segundo autores como Gatti (2010); Moriconi, Marconi, (2008) e Louzano et al. (2010), tem importância fundamental para atrair bons profissionais para a carreira do magistério. Países com resultados satisfatórios em avaliações padronizadas como o PISA (Programa Internacional de Avaliação de Estudantes) têm desenvolvido mecanismos efetivos para selecionar e treinar professores e buscam valorizar a carreira, oferecendo bons salários iniciais. Os professores da Finlândia e da Coréia do Sul, por exemplo, são selecionados entre os $10 \%$ e $5 \%$, respectivamente, entre os melhores alunos das turmas.

Moriconi e Marconi (2008), em estudos sobre os salários dos professores em outros países, demonstram que a remuneração, comparada à de outras profissões, tem um impacto significativo na possibilidade de que um graduado opte pela carreira do magistério, como no Reino Unido, onde este fator interfere na escolha 
dos que obtiveram formação a menos tempo e dos homens. Nos Estados Unidos, são as mulheres mais escolarizadas que têm a possibilidade maior em se tornar professoras quando a remuneração é melhor. Já no Japão, a valorização do professor também é um fator importante, pois eles são os funcionários públicos com maiores salários, além do grande investimento em profissionalização que o país realiza (FERRERI; BASSO, 2009).

Em uma pesquisa realizada em 2013 pela fundação educacional Varkey Gems, divulgada no sítio do Instituto Humanista Unisinos (2014), tendo por base o salário dos docentes, o respeito aos professores por parte dos alunos e o interesse pela profissão, o Brasil amarga o penúltimo lugar entre 21 países, em um ranking de valorização de professores. Numa escala que vai de 0 a 100, nosso país atingiu apenas 24 pontos, ficando apenas à frente de Israel. A China recebeu 100 pontos, sendo o país que mais valoriza a profissão, seguida da Grécia, com 73,7, e da Turquia, com 68. Os dados indicam que no Brasil menos de $20 \%$ dos entrevistados encorajariam seus filhos a serem professores. Já na Coréia do Sul, a porcentagem é superior a $40 \%$.

O piso salarial nacional dos professores de escola pública, com formação de nível médio e jornada de trabalho de 40 horas semanais, assegura o valor de $\mathrm{R} \$$ 2.135,64 para o ano de 2016, porém muitos estados não pagam nem mesmo esse valor. Um profissional de educação ganha, em média, $60 \%$ do que outros profissionais empregados no serviço público com a mesma formação (INSTITUTO HUMANISTA UNISINOS, 2014).

Há, contudo, fatores que colocam a carreira docente como atrativa para alguns jovens, como a possibilidade de estabilidade no emprego para os que são contratados e facilidade em passar no vestibular, devido à baixa concorrência. Outros fatores, apontados por Louzano et al. (2010, p. 548) são:

"1. Flexibilidade. A maioria dos professores tem a opção de trabalhar em tempo parcial e acomodar outros trabalhos dentro ou fora da escola onde atuam, de acordo com suas necessidades pessoais e financeiras;

2. Férias. Os professores têm geralmente férias mais longas (e mais frequentes) do que profissionais de outras áreas;

3. Taxas de desemprego baixas. Os professores raramente ficam desempregados por longos períodos de tempo;

4. Altruísmo. Os professores acreditam que podem contribuir para o desenvolvimento social".

Esses aspectos, somados à possibilidade de uma rápida inserção no mercado de trabalho, colocam a profissão docente, por vezes, não como primeira opção, mas como uma opção não descartada pelos jovens. Afinal, essa fase da vida é repleta de incertezas e desafios e a escolha profissional se difere indiscutivelmente pela importância de muitas outras que os jovens precisam fazer. É uma etapa de se fazer projetos, de se decidir que rumos a vida vai tomar, pois é no trabalho que esses jovens passarão grande parte de suas existências.

Torna-se crucial, portanto, que a escolha seja responsável e consciente, especialmente quando esta decisão tende a comprometer a vida de outras pessoas, como é a profissão docente. O professor é mais que um simples profissional, pois assume a tarefa não somente de preparar seus alunos para algo, 
mas de educar. Conforme diz Arroyo (2000, p. 54), "podemos aprender a ler, escrever sozinhos, podemos aprender geografia e a contar sozinhos, porém não aprendemos a ser humano sem a relação e o convívio com outros humanos que tenham aprendido essa difícil tarefa".

\section{Aspectos metodológicos da pesquisa}

Com a intenção de investigar a atratividade da carreira docente pela ótica de alunos do 3 ano do ensino médio de um município da região Centro Sul do Paraná, inserimos este estudo, quanto à natureza, nos fundamentos da pesquisa qualiquantitativa e, quanto aos objetivos, como pesquisa exploratória.

Como o próprio nome indica, a pesquisa quali-quantitativa representa a combinação das duas modalidades: qualitativa e quantitativa. Requer, portanto, a interpretação dos fenômenos e a atribuição de significados aos dados, como exigem os estudos qualitativos, porém não abdica do uso de recursos e de técnicas de quantificação, buscando traduzir informações em números para classificá-las e analisá-las, conforme estabelecem os estudos qualitativos (GIL, 2009). Neste estudo especificamente, buscou-se obter dados qualitativos sobre os motivos e influências que levaram os estudantes a desejar ou não a carreira docente, em especial, em cursar uma Licenciatura em Matemática, e dados quantitativos a respeito das intenções profissionais e do perfil dos estudantes.

Com relação aos objetivos do estudo, trata-se de uma pesquisa exploratória, pois diante da problemática ainda pouco definida sobre a não atratividade da carreira docente no Brasil, buscou-se obter informações ou dados mais esclarecedores e consistentes sobre ela. Esse tipo de pesquisa, segundo Gil (2009), tem por finalidade possibilitar melhor familiarização sobre um assunto, bem como provocar a construção de hipóteses e permitir a delimitação de uma temática e de seus objetivos, tornando o problema mais explícito. Em geral, envolve levantamento bibliográfico, realização de entrevistas, aplicação de questionários, dentre outros.

Em nosso caso, os dados foram coletados por meio de um questionário, contendo perguntas fechadas e abertas. Por meio das perguntas fechadas, buscouse obter dados sobre a idade, sexo, escolaridade da mãe, renda familiar e intenção profissional dos estudantes. Já por meio das perguntas abertas o intuito foi obter informações não previstas e dar oportunidade de expressão aos colaboradores da pesquisa (FIORENTINI; LORENZATO, 2009). Ou seja, nossa intenção foi captar os motivos e influências que levaram os jovens a desejar ser professor e, em especial, professor de Matemática, ou, em caso contrário, sobre o porquê a carreira docente não lhes é atrativa.

Os participantes foram 183 estudantes do $3^{\circ}$ ano do ensino médio do período diurno, de cinco colégios, sendo dois da rede particular de ensino (65 alunos) e três da rede pública (118 alunos). Dos últimos, um colégio está localizado na região central da cidade, outro em um dos bairros e, o terceiro, na área rural do município.

\section{Resultados e discussões}


Os atuais marcos legais para oferta do ensino médio, consubstanciados na Lei de Diretrizes e Bases da Educação Nacional (LDB no. 9394/96), representam um divisor na construção da identidade da etapa final da educação básica, tendo em vista que, historicamente, esse nível de ensino tem sido entendido sob duas perspectivas: por um lado, como etapa da escolarização voltada para o ingresso no ensino superior e, por outro lado, como preparação para atividades profissionais (RAMOS, CIAVATTA, 2011).

De acordo com a LDB, espera-se que ao final do ensino médio, etapa final da educação básica, o aluno tenha garantido: (1) a consolidação e o aprofundamento dos conhecimentos adquiridos no ensino fundamental, de forma que tenha condições de dar prosseguimento aos estudos; (2) o preparo básico para o trabalho e a cidadania, para continuar aprendendo, de modo a ser capaz de se adaptar com flexibilidade a novas condições de ocupação ou aperfeiçoamento posteriores; (3) o aprimoramento como pessoa humana, incluindo a formação ética e o desenvolvimento da autonomia intelectual e do pensamento crítico; (4) a compreensão dos fundamentos científico-tecnológicos dos processos produtivos, relacionando a teoria com a prática (BRASIL, 1996, art. 35).

Dos estudantes do 3 o ano do ensino médio investigados neste estudo, 94\% estão na faixa etária de 16 e 17 anos, sendo $51 \%$ do sexo feminino e $49 \%$ do sexo masculino. Desses estudantes, $72 \%$ declararam que não trabalham, $14 \%$ que trabalham e contribuem financeiramente com a família e os demais, $14 \%$, que trabalham, mas não ajudam a família financeiramente, conforme indica o gráfico a seguir. Dos entrevistados, $88 \%$ que trabalham são provenientes de instituição pública.

Gráfico 1: Comparação entre os estudantes que trabalham e contribuem financeiramente com a família

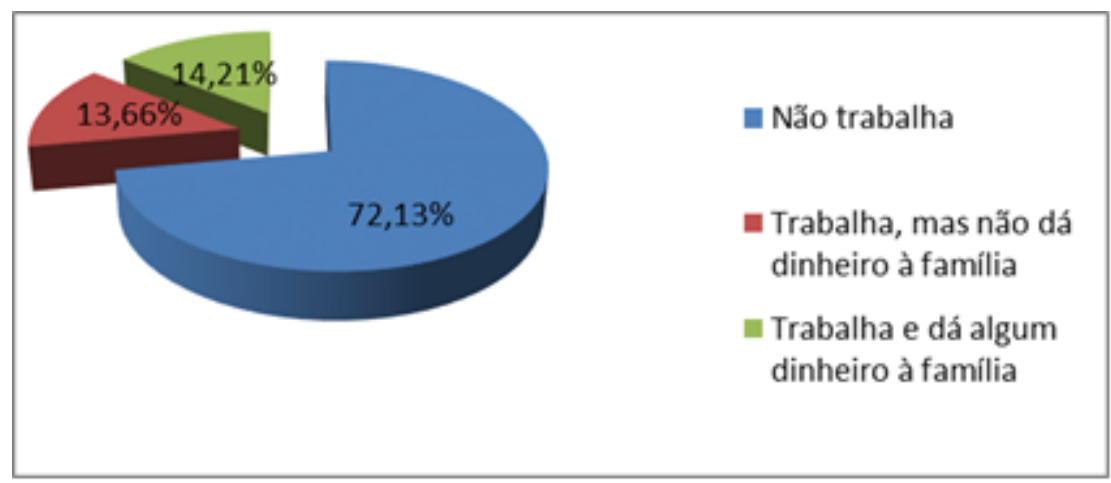

Fonte: arquivo das autoras

Em relação à renda familiar mensal dos alunos, os que frequentam a rede pública de ensino apresentam renda significativamente mais baixa do que os que frequentam a rede particular, pois $45 \%$ ganham menos que dois mil reais; $42 \%$ recebem de dois a cinco mil reais e $13 \%$ de cinco a dez mil reais. Já da rede particular, constata-se que $16 \%$ possuem renda familiar menor que dois mil reais; $34 \%$, de dois a cinco mil reais; $41 \%$, de cinco a dez mil reais e $9 \%$ acima de dez mil reais. 
Quadro 1: Renda familiar mensal dos estudantes entrevistados

\begin{tabular}{ccc} 
& $\begin{array}{c}\text { Instituição } \\
\text { Pública }\end{array}$ & $\begin{array}{c}\text { Instituição } \\
\text { Privada }\end{array}$ \\
\hline Renda $<2$ mil reais & $44 \%$ & $16 \%$ \\
\hline 2 mil $<$ renda $<5$ mil & $42 \%$ & $34 \%$ \\
\hline 5 mil < renda $<10$ mil & $14 \%$ & $41 \%$ \\
\hline Mais de 10 mil reais & $0 \%$ & $9 \%$
\end{tabular}

Sobre a escolaridade materna, foi possível verificar que na rede pública de ensino, $35 \%$ das mães possuem ensino fundamental incompleto; $17 \%$, fundamental completo; $28 \%$, ensino médio completo; e apenas $20 \%$ concluíram o ensino superior. Já na rede privada, não tivemos apontamento de mães com ensino fundamental incompleto, sendo que $3 \%$ possuem o ensino fundamental completo; $29 \%$, ensino médio completo; e $68 \%$, ensino superior completo.

A respeito da intenção em cursar o ensino superior, todos os estudantes das instituições privadas demonstram interesse em prestar vestibular; já 19\% dos entrevistados das instituições públicas afirmam que pretendem realizar cursos técnicos, trabalhar na lavoura, seguir carreira militar, entre outras atividades, e não acreditam que o diploma de ensino superior representa garantia de um bom emprego e salário estável.

Interrogados sobre como consideram a profissão docente, os estudantes indicaram que reconhecem o valor do professor e consideram o trabalho nobre, difícil, de muita responsabilidade e fundamental para a formação cidadã e profissional dos indivíduos. Frases como: "todo mundo tem que passar pela mão de um professor"; "o professor é a base para a formação de profissionais capacitados", "são eles que nos preparam para o futuro", "deveria ser o profissional mais bem pago de todos", foram constantes entre as respostas. Os jovens avaliam a profissão como importante para o desenvolvimento da sociedade, porém apontam para a desvalorização e para o desrespeito com que a classe docente tem sofrido dentro e fora das escolas.

Quando perguntados se em algum momento de suas vidas tiveram a intenção de ser professor ou se ainda têm esta pretensão, $21,5 \%$ dos estudantes da rede particular de ensino e $44 \%$ da rede pública responderam que sim, respectivamente 14 e 52 alunos. Sobre os motivos e influências que os levaram a desejar a carreira docente, os estudantes apontaram para a aptidão ou dom que acreditam ter para o magistério, para o caráter gratificante e desafiador da profissão, para o anseio de trabalhar com crianças e, em especial, para o desejo de contribuir para um futuro melhor do país. A influência da família em suas aspirações também foi apontada por cinco estudantes.

Atualmente, entretanto, percebe-se que as intenções dos estudantes se alteraram e suas as opções por cursos superiores são ecléticas e um pouco confusas. Como a maioria dos estudantes (92\%) afirmou não ter realizado um teste vocacional, suas ideias são bastante indefinidas quanto à escolha profissional. Mesmo estando na fase de conclusão da escolarização básica, os indecisos representam um número expressivo, pois $19 \%$ dos alunos da escola pública que pretendem realizar curso superior e $14 \%$ da privada ainda não se decidiram pelo 
curso que pretendem prestar vestibular. Em relação às duas opções de curso, muitos alunos nomeiam cursos que não são da mesma área, por exemplo: 1a opção: Medicina e 2a Opção: Engenharia Civil, Direito ou Fisioterapia; Medicina Veterinária e História, dentre outros.

O gráfico a seguir relaciona os cursos separados por áreas: Biológicas, Exatas e Humanas. Criamos também uma subdivisão, que se refere a nossa pesquisa Pedagogia e Licenciaturas, para fins de comparação.

Gráfico 2: Áreas apontadas como primeira opção dos estudantes para prestar vestibular

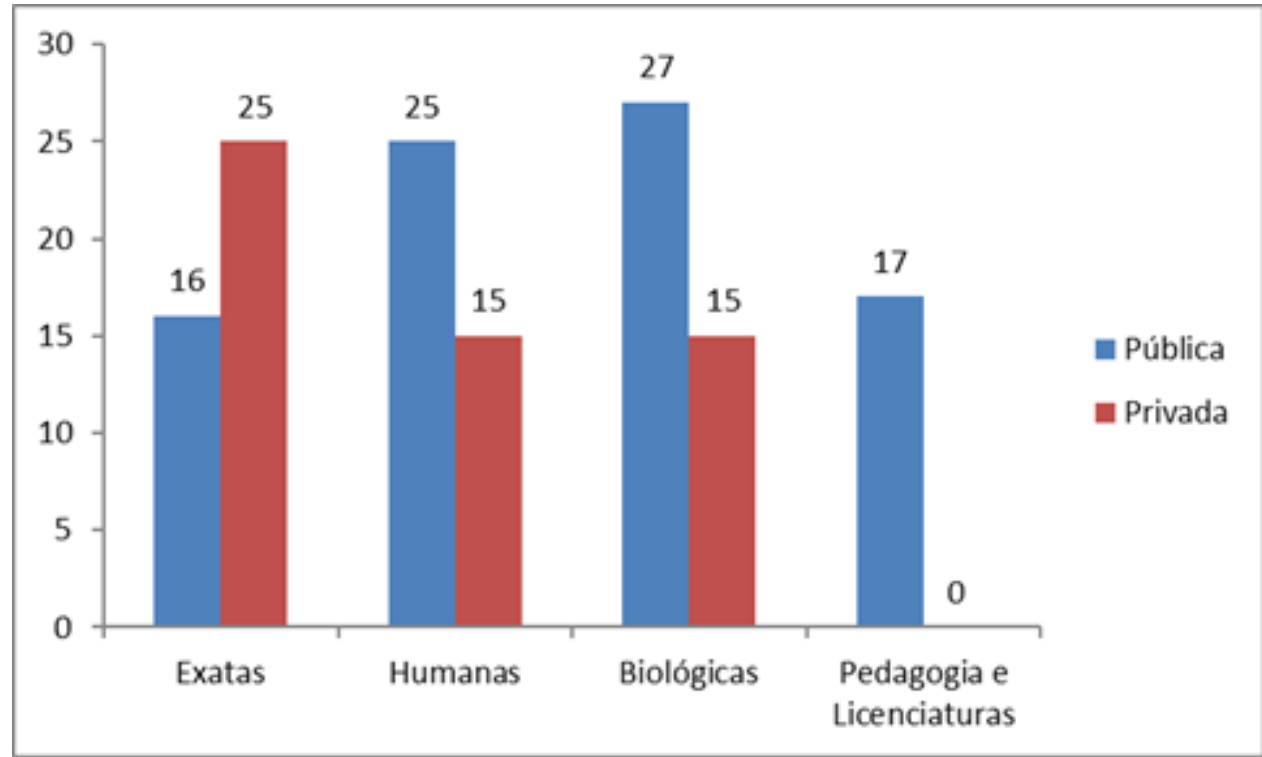

Fonte: arquivo das autoras

Considerando que 14 estudantes da rede particular de ensino e 52 da rede pública em algum momento do processo de escolha profissional almejou trabalhar como professor, conforme já apontado, observa-se no gráfico, que a aspiração pela profissão docente se reduziu consideravelmente com o passar dos anos. Dos estudantes dos colégios particulares, nenhum deles indicou como 1a opção cursos ligados à formação docente, não colocando esta carreira como prioridade. Dos 118 estudantes dos colégios públicos, 17 indicaram como 1a opção cursos de Pedagogia ou Licenciatura (14\% do total), sendo, especificamente, 6 para o curso de Educação Física, 1 para Filosofia, 2 para História, 1 para Espanhol, 2 para Matemática e 5 para Pedagogia. Outros cursos, como Geografia, Química e Biologia, sequer foram cogitados. Interessante observar que dos 17 alunos que optam pela carreira docente, 12 estudam no colégio localizado na área rural do município.

Sobre os motivos que os levaram a descartar a carreira docente, os alunos mencionam a falta de respeito pelos professores nas salas de aula, o estresse a que os docentes são submetidos, a desvalorização e a baixa remuneração dos profissionais da educação. Esses fatores são também apontados por aqueles que nunca desejaram ser professor, indicando ainda a falta de identificação pessoal ou profissional com a carreira. As respostas a seguir demonstram algumas opiniões dos estudantes: 
Não gosto de estudar. Então ser professor exigiria muito de mim. Prefiro seguir outra profissão. (estudante da rede pública)

Não é uma profissão muito boa. Trabalha muito, ganha pouco e quando chega o tempo de se aposentar, está com muitos problemas de saúde. (estudante da rede pública).

Não quero ser professor devido ao pouco reconhecimento, tanto salarial como social. (estudante da rede particular)

Não tenho dom para ensinar, não tenho paciência. (estudante da rede pública)

Acho que professor trabalha demais e tem que aguentar aluno que não é educado em casa, além de ganhar pouco. (estudante da rede pública)

Pela desvalorização do professor, muito esforço e pouco reconhecimento, não quero isso prá mim. (estudante da rede pública)

Quando era criança sonhava em ser professora. Hoje percebo que não teria paciência para ensinar e o pouco valor do professor me desmotivou. (estudante da rede particular)

Com relação a ser professor de Matemática, de um universo de 183 estudantes, somente treze indicaram que já tiveram a intenção de ser professor de Matemática, sendo onze da rede pública e dois da rede particular de ensino. Desses, porém, somente dois do ensino público mantém sua pretensão em ser professor desta disciplina, pois indicaram como primeira opção prestar vestibular para Matemática. As justificativas dos estudantes por não almejar a profissão docente nessa disciplina se resumem nas seguintes colocações: (1) porque não gosto dessa matéria; (2) não sou bom em cálculos; (3) porque é uma disciplina muito complicada; (4) vou mal nessa matéria; (5) não é utilizada na vida das pessoas.

\section{Considerações finais}

Esta pesquisa, realizada em turmas do $3^{\circ}$ ano do ensino médio, indica que os estudantes investigados percebem a profissão docente como gratificante e de muita responsabilidade, entendendo a relevância do professor na sociedade. Eles formação ampla dos indivíduos, tanto profissional, como humana e cidadã 
Uma parcela significativa dos estudantes revelou que já teve a intenção de ser professor, em especial pelo caráter altruísta da profissão, ou seja, por acreditar que por meio dela poderiam contribuir para o desenvolvimento social, reforçando a ideia de que é preciso vocação para ensinar. Os dados indicam, entretanto, que as intenções se alteraram e que, atualmente, a grande maioria não percebe a carreira docente como interessante, inclusive por aqueles que em outros tempos desejaram ser professor. Do grupo inquirido, nenhum estudante da rede particular e $14 \%$ dos estudantes da rede pública indicaram como primeira opção prestar vestibular para um curso de Licenciatura ou Pedagogia. Salários baixos, pouca valorização, rotina desgastante, desrespeito em sala de aula, violência nas escolas e falta de identificação com a profissão, são os principais fatores apontados pelos estudantes como motivos para não seguir a carreira docente, vista como cada vez mais complexa.

Outro dado que este estudo pôde confirmar é que os candidatos à docência são oriundos de escola pública, com renda familiar menor que dois mil reais e filhos de mães com ensino fundamental incompleto. Ou seja, o perfil atual dos candidatos à docência no município é de indivíduos com baixo poder aquisitivo e com menor bagagem cultural, em geral, com restrições para o acesso à leitura, cinema, exposições e eventos.

Esses dados representam um alerta não somente para a região investigada, mas também para o Brasil, que já experimenta as consequências do baixo interesse pela docência, tendo em vista a rotatividade de docentes nas escolas e a falta de professores em muitas salas de aulas, especialmente na área de exatas. Considerando resultados apontados por outros pesquisadores e as informações trazidas em nosso estudo, é possível prever que o problema tende a se intensificar com a expansão de matrículas projetadas para os próximos anos e com a extensão da obrigatoriedade de escolarização de crianças e jovens de 4 a 17 anos, conforme preconiza a recente legislação (Lei 12796, de 04 de abril de 2013).

Em se tratando da disciplina de Matemática, percebe-se que grande parte do grupo investigado não quer ser professor dessa disciplina por não gostar dessa área e por considerá-la difícil e sem relação com o cotidiano, o que representa um indicativo para os cursos de Licenciatura em Matemática que precisam investir na formação de professores competentes, com espírito inovador e suscetível às mudanças que se fazem necessárias no ensino de Matemática.

Por fim, não há dúvidas de que para atrair estudantes concluintes da escolarização básica para a carreira docente é preciso melhorar os incentivos salariais, as condições de trabalho e o status social da profissão e, mais que isso, criar mecanismos para atrair jovens mais bem preparados para a profissão. Contudo, por ser a profissão docente de grande valor social, essa decisão deve ser consciente e assumida a partir de reflexões e de muito comprometimento, considerando os desafios e responsabilidades concernentes à profissão. 


\title{
Teaching profession: high school students aspirations about being a Mathematics teacher
}

\begin{abstract}
This article aims to discuss the attractiveness of the teaching profession from the perspective of 3rd year of high school students, especially about being a mathematics teacher. Quantitative data about the professional intentions of five colleges students of Paraná municipality were sought, as well as qualitative data on the reasons and influences that led these students to desire or not a teaching career, using as instrument a questionnaire with open and closed questions. The data indicate that students consider the teaching profession important and of great responsibility, but the vast majority does not intend to follow a teaching career, due to the profession lack of attractiveness. On the desire to become a mathematics teacher, the number is almost negligible and the reasons are summarized in not liking the discipline, having great difficulty in assimilating the content and not seeing the purpose of what they learn in school mathematics.
\end{abstract}

KEYWORDS: High school. Career choice. Mathematics teacher. 


\section{NOTAS}

\section{REFERÊNCIAS}

ARROYO, M. Ofício de Mestre: Imagens e auto-imagens. Petrópolis: Vozes, 2000.

BRASIL. Lei de Diretrizes e Bases da Educação Nacional (de 20 de dezembro de 1996). Lei № 9394. Brasília, Congresso Nacional, 1996.

BRASIL. Lei $N^{\circ} 12796$ (de 04 de abril de 2013). Brasília, Congresso Nacional, 2013.

CHALITA, G. Educação: a solução está no afeto. 6 ed. São Paulo: Gente, 2001.

FELZ, J . Reflexões sobre o ser professor: a construção de um professor intelectual. In: PERUZZO, C. M. K.; SILVA, B. S.(Org.). Retrato do Ensino em Comunicação no Brasil. São Paulo/ Taubaté: Intercom/ Unitau, 2003, v. 16, p. 179-187.

FERRERI, H. G.; BASSO, F. C. Políticas públicas sistemas educacionais do Brasil e do Japão. Revista Jovens Pesquisadores. Ano VI, n. 10, jan./jun. 2009.

FIORENTINI, D.; LORENZATO, S. Investigação em educação matemática: percursos teóricos e metodológicos. 2ed. Campinas: Autores Associados, 2009.

GATTI, B. A.; TARTUCE, G. L. B. P.; NUNES, M.; ALMEIDA, P. A. Atratividade da carreira docente no Brasil. In: FUNDAÇÃO VICTOR CIVITA . Estudos e pesquisas educacionais. São Paulo: FVC, 2010, v. 1, n.1. Disponível em:

<http://www.fvc.org.br/estudos-e-pesquisas/avulsas/estudos1-4-atratividadecarreira.shtml?page=1> Acesso em 10 fev. 2015 .

GIL, A. C. Como elaborar projetos de pesquisa. 4ed. São Paulo: Atlas, 2009.

GRAMANI, M. C. N.; SCRICH, C. R. Influência do desempenho educacional na escolha da profissão. Cadernos de Pesquisa - Fundação Carlos Chagas, v. 42, p. 868-883, 2012.

HOUAISS, A. Dicionário eletrônico Houaiss da Língua Portuguesa. Rio de Janeiro: Objetiva. Versão 1.0. 1 [CD-ROM]. 2001. 
INSTITUTO HUMANISTA UNISINOS. A dura realidade de ser professor no Brasil (notícias). 2014. Disponível em <http://www.ihu.unisinos.br/noticias/527476> Acesso em 15 fev. 2015.

LIMA, J. M. A. O papel do professor nas sociedades contemporâneas. Educação, Sociedade e Cultura. n. 6, 1996, p. 47-72.

LOUZANO, P.; ROCHA V.; MORICONI, G. M.; OLIVEIRA, R. P. Quem quer ser professor? Atratividade, seleção e formação docente no Brasil. Estudos em Avaliação Educacional, São Paulo, v. 21, n. 47, p. 543-568, set./dez. 2010.

MIZUKAMI, M. da G. N. Docência, trajetórias pessoais e desenvolvimento profissional. In: REALI, A M. de M. R. e MIZUKAMI, M. da G. N.(Org.) Formação de professores: tendências atuais. São Carlos, SP.: Editora da UFSCar, 1996. MORICONI, G. M.; MARCONI, N. Os salários dos professores públicos são atrativos no Brasil?. 2008. Disponível em:

$<$ www.anpec.org.br/encontro2008/artigos/200807211605210-.pdf> Acesso em 20 jan. 2015.

RAMOS, M. N.; CIAVATTA, M. Ensino Médio e Educação Profissional no Brasil: dualidade e fragmentação. Retratos da Escola. v. 5, p. 27-41, 2011.

SILVA, M. C. A atuação da orientação pedagógica como mediador na formação de professores formadores. Especialização em Orientação Educacional e Pedagógica (monografia). Universidade Cândido Mendes - Instituto a Vez do mestre. Rio de janeiro, 2010.

TARTUCE, G. L. B. P.; NUNES, M.; ALMEIDA, P. A. Alunos do Ensino Médio e a atratividade da carreira docente no Brasil. Cadernos de Pesquisa - Fundação Carlos Chagas, v. 40, p. 445-477, 2010. 
Recebido: 10 abri. 2015

Aprovado: 13 jul. 2016

DOI: http://dx.doi.org/10.3895/rbect.v9n2.2879

Como citar: FILLOS, L. M.; ZEN, P. D.; CAETANO, J. J. Profissão docente: aspirações de estudantes do

ensino médio sobre ser professor de Matemática. Revista Brasileira de Ensino de Ciência e Tecnologia, v. 9, n. 2, 2016. Disponível em: <https://periodicos.utfpr.edu.br/rbect/article/view/2879>. Acesso em: xxx.

Correspondência:

Av Monteiro Lobato, 205, 84010-060 - Ponta Grossa - Paraná

Direito autoral: Este artigo está licenciado sob os termos da Licença Creative Commons-Atribuição 4.0

Internacional.

(c) (1) 